\title{
Reflexões que Precisam Ser Feitas sobre o Uso dos Chamados "Materiais Concretos" para a Aprendizagem em Matemática
}

\author{
Célia Maria Carolino Pires \\ Professora, PUC/SP \\ celia@pucsp.br \\ edmat@pucsp.br
}

\begin{abstract}
Resumo
O presente artigo tem como objetivo compartilhar algumas reflexões sobre o uso dos chamados "materiais concretos" para a aprendizagem em Matemática, especialmente nos anos iniciais. Retoma alguns contextos em que esses materiais, em particular o Material Dourado Montessori, apareceram no cenário educacional e questiona seu uso em função do que pesquisas recentes revelam sobre conhecimentos prévios e hipóteses das crianças. Pretende mostrar, pelo resgate de alguns episódios, que a produção de conhecimentos didáticos é um processo dinâmico, em constante transformação, que traz questionamentos para a prática e formação de professores.
\end{abstract}

Palavras-chave: Conhecimentos Prévios. Hipóteses das Crianças. Novas investigações. Materiais concretos.

\section{Reflections That Need To Be Made On The Use Of The Materials Called For Specific Learning In Mathematics}

\begin{abstract}
This article aims to share some reflections on the use of so-called "concrete materials" for learning in mathematics, especially in early years. Incorporates some contexts in which these materials, particularly the Golden Montessori Material, appeared in educational scenario and questions its use according to recent surveys reveal that prior knowledge and assumptions about children. It intends to show, by rescue of some episodes, the production of educational knowledge is a dynamic, constantly changing, which raises questions for practice and teacher training.
\end{abstract}

Keywords: Preliminary knowledge. Assumptions of the children. Concrete materials 


\section{Breve retrospectiva}

Nossos estudos, reflexões e práticas sobre ensinar e aprender Matemática iniciaram-se na década de 80, quando integramos a Equipe Técnica de Matemática da Coordenadoria de Estudos e Normas Pedagógicas - CENP, órgão da Secretaria Estadual de São Paulo.

Dentre os vários projetos desenvolvidos por essa equipe, destacamos a elaboração de um material de apoio à prática dos professores dos quatro primeiros anos do Ensino Fundamental que se denominou "Atividades Matemáticas". O material buscava a construção de alternativas que pudessem dar respostas ao desafio de ensinar Matemática às crianças, sabendo-se que essa tarefa era realizada por professores não especialistas no assunto e, muitas vezes, com experiências pessoais negativas, na relação com a Matemática.

Nossa equipe inicial era constituída por professoras de Matemática efetivas da rede pública que eram selecionadas e convocadas para trabalhar na CENP. A tarefa de propor atividades para crianças aprenderem Matemática, que poderia parecer simples para um especialista, mostrou, logo de início, grande complexidade.

Constituímos mais que um grupo de elaboradores de material, um grupo de estudiosos do assunto. No início do projeto, tivemos assessoria de pesquisadores franceses, como o professor Jacques Coulomb, ligados ao Institut National de Recherche Pédagogique - INRP, que discutiam bases teóricas e atividades que poderiam ser oferecidas às crianças. Esse trabalho era coordenado pelos professores Lydia Condé Lamparelli e Almerindo Marques Bastos.

Nessa época, a rede pública estadual estava sob a orientação de documentos como os "Guias Curriculares" e os "Subsídios para a implementação do Guia Curricular de Matemática", editados na década de 70, com influência marcante das ideias do Movimento Matemática Moderna e, especialmente, das teorias piagetianas.

As ideias de Piaget sobre a construção do número chegavam ao Brasil e, com elas, a importância de se trabalhar as chamadas atividades pré-numéricas para possibilitar a construção do conceito de número pela criança. $\mathrm{O}$ trabalho pedagógico com número enfatizava o papel das atividades de seriação, classificação e correspondência termo a termo para construção desse conceito. Materiais como os Blocos Lógicos divulgados por Zoltan Dienes, em visitas ao Brasil, eram muito usados como recurso em atividades que visavam ao desenvolvimento do raciocínio lógico, tomando por base o uso de materiais denominados concretos.

Defendia-se a necessidade de a criança fazer mais que a simples associação de um símbolo à quantidade, percebendo que cada número designava uma coleção de coleções com a mesma quantidade de elementos. Assim, trabalhavam-se as noções de conjunto, pertinência e inclusão e colocava-se como importante que a criança distinguisse número de numeral. 
A aprendizagem do sistema de numeração decimal apoiava-se no trabalho de atividades com uso do Material Dourado Montessori (em diferentes bases e na base dez), em que se apostava no fato de que mediante a manipulação desse material as crianças se apropriariam das características do sistema de numeração. Uma dessas atividades era o jogo do "Nunca dez". Nele, cada aluno, na sua vez de jogar, lançava por exemplo um dado de pontos e retirava na caixa do material dourado igual quantidade de cubinhos. Quando ele conseguisse mais do que dez cubinhos trocava-os por uma barra que estava na caixa do material. Quando conseguisse dez barras trocava por uma placa. Vencia o jogador que conseguisse primeiro dez placas ou um número de placas, antecipadamente, combinado.

Seguia-se a organização linear, ensinando-se primeiro os números até dez, depois de 11 a 20 e assim por diante. Geralmente, no primeiro ano de escolaridade as crianças só teriam contato. na escola, com os números até 99.

Nesse período, as principais referências bibliográficas de Equipe de Matemática da CENP eram os livros de Piaget: A Construção do Real na Criança (1970); A Formação do Símbolo na Criança. Imitação, jogo e sonho, imagem e representação (1971); A Linguagem e o Pensamento na Criança (1959); A Epistemologia Genética (1971); Seis Estudos de Psicologia (1967); A Gênese do Número na criança (1981). Também era muito estudado o livro As seis etapas do processo de aprendizagem, de Zoltan Dienes (Editora EPU / Primeiros passos em matemática; v. 1, 2 e 3).

O Projeto "Atividades Matemáticas", embora inicialmente atrelado às ideias propostas nos documentos curriculares elaborados ao longo da década de 1970, trouxe contribuições que serviram de base para um novo documento curricular da Secretaria Estadual da Educação, denominado Proposta Curricular para o Ensino de Matemática: $1 .^{\circ}$ Grau. São Paulo: SE/CENP, 1986, que substituiu os Guias Curriculares.

Nesse novo documento, a Equipe Técnica da CENP explicitava sua crítica ao trabalho excessivamente apoiado na linguagem simbólica dos conjuntos como algo a ser revisto. Pode-se dizer que na década de 80 , tirou-se a ênfase no uso de materiais como os Blocos Lógicos e a Escala Cuisenaire, mas a utilização do Material Dourado Montessori continuou bastante presente.

$\mathrm{Na}$ Proposta Curricular para o Ensino de Matemática, da década de 80, lia-se:

(...) Pode-se estudar os Números a partir de sua organização em conjuntos numéricos, passando-se dos Naturais aos Inteiros, aos Racionais, aos Reais, tendo como fio condutor as propriedades estruturais que caracterizam tais conjuntos, ou pode-se estudá-los acompanhando a evolução da noção de número a partir tanto de contagens como de medidas, sem ter ainda as propriedades 
estruturais claramente divisadas, deixando-se guiar pelo fio condutor que a História propicia e trocando assim uma sistematização prematura por uma abordagem mais rica em significados. Nessa proposta, optou-se por essa última abordagem. (Proposta Curricular, 1986, p.11)

Com relação ao ensino de números no Ciclo Básico (ou seja, ao período correspondente aos dois anos iniciais do Ensino Fundamental de 8 anos) o documento destaca a importância de trabalhar com atividades de classificação, seriação e simbolização como pré-requisito à construção do conceito de número, sob a alegação de que as crianças entenderiam o número como uma síntese das ideias de classe e de ordem.

O documento, ao expor os objetivos para o Ciclo Básico, destacava o que era esperado dos alunos, como mostra a transcrição a seguir.

Perceba que cada número natural designa uma coleção de coleções com a mesma quantidade de elementos e que ocupa um lugar na série numérica.

Realize a contagem dos elementos de uma coleção e represente simbolicamente (de 1 a 9), bem como, desenvolva o conceito de zero.

Compreenda a estrutura do sistema de numeração decimal.

Compreenda o significado das operações básicas com números naturais e identifique, em situações-problema, as ideias envolvidas em cada uma.

Construa os fatos fundamentais relativos às quatro operações.

Utilize as propriedades das operações na realização de cálculos.

Domine as técnicas operatórias da adição, multiplicação e subtração com números naturais menores que 1.000.(Ibidem, p.23)

Em relação a orientações didáticas, a Proposta Curricular para o Ensino de Matemática fazia as seguintes observações:

Muito mais que a simples associação de um símbolo à quantidade, deseja-se que a criança perceba que cada número natural designa uma coleção de coleções com uma mesma quantidade de elementos.

Convém lembrar, que a formação da ideia de número é um processo complexo que se dá, por abstração, a partir de ações que envolvem classificações, comparações, relações de inclusão, entre outras.

O desenvolvimento dessa ideia dá ao longo dos 8 anos do $1^{\circ}$ grau: desde os processos de contagem direta, que abrangem os números naturais, até os processos de medidas, que conduzem aos números irracionais. (Ibidem, p.27). 
A referência à exploração da contagem de rotina e à comparação de quantidades, o documento apontava:

Explorar a contagem de rotina (que a maioria das crianças já domina, ao ingressar no Ciclo Básico), através de cantigas de roda, jogos, dramatizações etc. Com essas atividades pretende-se avaliar o conhecimento, que a criança já possui, do número natural, bem como o nível desse conhecimento. É importante partir de onde o aluno já se encontra. (Ibidem, p.28)

As experiências que a criança desenvolve, para a formação do conceito de número e para operar com eles, têm como suporte, relações que se estabelecem entre os elementos de duas coleções: seja comparando intuitivamente duas ou mais quantidades, fazendo correspondência termo a termo, seja percebendo a inclusão de um conjunto em outro, seja ordenando ou classificando objetos, a partir de critérios que lhe pareçam válidos.

Através de pesquisas pedagógicas, constatou-se que crianças de 7 anos procedem de diferentes maneiras, quando comparam as quantidades de elementos de duas coleções. Tais procedimentos estão relacionados com a ordem de grandeza dos elementos das mesmas; assim, se as coleções possuem até 6 objetos cada uma, a comparação é feita por percepção global.

No caso em que as duas coleções tenham quantidades de objetos mais ou menos entre 7 e 15, o procedimento que a criança acaba descobrindo é a formação de pares, onde cada par é constituído por um elemento de cada coleção. Quando se trata de coleções em quantidades de elementos maiores que 15, a formação de pares de torna difícil (principalmente se tratar de representação gráfica) e, nesse caso, a tendência é comprar grupos de elementos de cada coleção.(Ibidem, p.28)

O documento chamava a atenção para a introdução dos símbolos numéricos de 1 a 9 e também para a construção da sequência numérica, pelo acréscimo sucessivo de um elemento:

Trabalhando a ideia de simbolização, as crianças são levadas a representar simbolicamente diferentes quantidades, por meio de tracinhos, quadrículas etc., até chegar ao símbolo numérico.

A introdução desses símbolos numéricos deve ser feita a partir de situações que sejam significativas para a criança: registro de resultados de um jogo, da sua idade, do total de crianças de seu grupo, etc. Um jogo interessante, é o dominó de símbolos e quantidades, onde cada símbolo deverá ser justaposto à quantidade correspondente. 
(...) Construindo coleções de objetos, onde cada uma tem um elemento a mais que a anterior, obtemos a sequência numérica, onde está presente o aspecto ordinal do número, ou seja: a criança inclui "1 em 2", "2 em 3", "3 em 4" etc. (Ibidem, p.28)

Dentre as várias sugestões para o trabalho, aparecem propostas de atividades para a e representação dos números naturais na reta numérica:

Através de situações de jogos, em que cada criança deva ocupar uma "casa", em uma fileira de quadros desenhados no chão, os alunos poderão descobrir a necessidade de: começar a numerar as casas a partir de uma origem; colocar as casas em distâncias iguais, uma das outras. . (Ibidem, p.29)

Com relação ao Sistema de Numeração Decimal, o documento destaca as atividades de agrupamentos e trocas, de forma bastante detalhada:

Ao propiciar experiências com agrupamentos e trocas em bases variadas, estaremos levando os alunos a compreender o processo de agrupamentos e trocas, na base 10, que caracteriza o sistema posicional de numeração decimal. As atividades desenvolvidas deverão permitir que as crianças entendam que é possível designar o número de objetos de uma coleção finita, fazendo agrupamentos e nomeando-os, ou realizando trocas, com valores preestabelecidos. (Ibidem, p.29).

De 1986 até o presente momento, decorreram vinte e seis anos em que novas pesquisas foram realizadas, trazendo novas contribuições.

Do nosso ponto de vista, elas trazem a necessidade de rever práticas que foram idealizadas em outras concepções. No entanto, essa discussão, ao que tudo indica, não está sendo feita com a profundidade exigida, nem na academia, nem nas escolas. Por esse motivo, trazemos neste artigo, nossas preocupações e um convite à reflexão sobre o uso dos chamados "materiais concretos" para a aprendizagem em Matemática nos anos iniciais, tomando como exemplo aquele que parece ser o de utilização mais aceita: o Material Dourado Montessori.

\section{A magia do Material Dourado}

Mesmo não sendo mais "dourado" como idealizou a educadora italiana Maria Montessori - um material feito com contas douradas dispostas em araminhos para que crianças com deficiência visual pudessem manipular e perceber as quantidades - o 
material comercializado em madeira com "cubinhos, barras, placas e cubão" foi (é) visto como um recurso quase indispensável de "concretização" das regras criadas pelos hindus e divulgadas pelos árabes e que nos permitem representar os números e operar com eles. De certo modo, oculta-se a história de construção do sistema e passa-se a impressão de que o Sistema de Numeração Decimal é tão ligado ao material dourado que é difícil pensar que os hindus não o utilizavam.

Quando conheci o material dourado, já sendo professora de Matemática, também fiquei encantada com ele. Na verdade, hoje avalio que devo ter ficado encantada com a descoberta de que nas escritas numéricas e nos algoritmos havia uma explicação que antes, ninguém nos havia contado. Vivíamos um período de descobertas e nos filiamos à ideia de que era preciso ensinar/aprender Matemática não pela memorização de regras, mas pela compreensão do que estávamos fazendo e porque estávamos fazendo, convicção que dura até hoje..

A partir dessa época, também começamos a descobrir que são as crianças que constroem seus conhecimentos e que cabe a nós professores não o papel de transmitir conhecimentos, mas sim criar situações em que elas coloquem em ação seus conhecimentos prévios, formulem hipóteses e dessa forma construam aprendizagens significativas sobre conceitos e procedimentos matemáticos.

Em função dessas ideias, pesquisadores como Fayol (1996) e Lerner (1996), por exemplo, dedicaram-se a investigar conhecimentos prévios e hipóteses das crianças e ousaram fazer perguntas a elas. Descobriram coisas que não sabíamos até então, e que sintetizamos na sequência.

- O conceito de número pelas crianças é construído com base tanto no desenvolvimento cognitivo quanto na interação com o ambiente social em que convivem. A criança entende o número a partir de experiências significativas.

- As crianças elaboram suposições em relação à notação numérica muito antes de ingressarem na escola. Elas formulam critérios de comparação de escritas numéricas fazendo a relação entre a posição e o valor dos algarismos quando interagem com a escrita numérica.

- Percebem regularidades e procuram representar os números pela escrita e isso ocorre na interação da criança em um contexto real, no contato com números familiares e frequentes.

- As crianças supõem que a numeração escrita se vincula estritamente a numeração falada e sabem que em nosso sistema de numeração a quantidade de algarismos está relacionada à magnitude do número representado.

- Na aprendizagem dos números tem papel importante o uso de referências do universo numérico cotidiano das crianças como sua idade, a data, o número 
de sua casa, a contagem de figurinhas, a organização de álbuns, as placas de carros, entre outros.

- As sequências didáticas para a construção das aprendizagens das crianças sobre os números devem ter como questão norteadora "Para que servem os números" explorando-se as funções sociais dos números: função cardinal. Função ordinal, função de codificação. Função de medida.

Com essas novas descobertas da pesquisa caberia, a meu ver, o aparecimento de perguntas tais como: tem sentido insistir em atividades pré-numéricas condição de pré-requisito á construção das primeiras ideias sobre número natural? O Material Dourado é de fato um material "concreto" que auxilia as crianças nas suas aprendizagens do sistema numérico, considerando-se as hipóteses que elas tem sobre as escritas numéricas? Em que situações da vida cada criança, sem ser na escola, um número como 12 aparece na forma de uma barra e dois cubinhos?

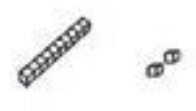

Ou o número 12 vai aparecer mais provavelmente na contagem de uma dúzia de objetos, ou no número de sua casa que pode ser 12 , ou de seu lugar na fila de crianças da classe, que pode ser o $12^{\circ}$ ?

E o que dizer da associação de um total de 1245 alunos de uma escola à representação:
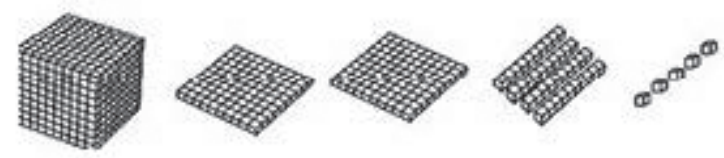

\section{Novos desafios, novos conhecimentos, novas escolhas}

Questões como essas estiveram muito presentes quando, em 1996 e 1997, participei da equipe de elaboração dos Parâmetros Curriculares Nacionais (PCN), do Ministério da Educação, para os anos iniciais do ensino fundamental, em que foram discutidas novas perspectivas para o ensino de Matemática, apoiadas no que já se tinha avançado em termos de pesquisa sobre a aprendizagem matemática das crianças. Em particular, as ideias sobre a aprendizagem dos números e do sistema de numeração. Selecionamos alguns trechos das orientações didáticas contidas nesse documento, com a finalidade de mostrar as concepções ali presentes. 
Uma das observações refere-se à atenção a ser dada aos conhecimentos prévios das crianças no início da escolaridade:

A criança vem para a escola com um razoável conhecimento não apenas dos números de 1 a 9 , como também de números como $12,13,15$, que já lhe são bastante familiares, e de outros números que aparecem com frequência no seu dia-a-dia - como os números que indicam os dias do mês, que vão até 30/31. (PCN/EF/Matemática/ Anos Iniciais, p.65)

O documento apresenta um rol de sugestões no sentido de que as atividades em sala de aula devem estar relacionadas ao uso que as crianças já fazem dos números:

Desse modo, as atividades de leitura, escrita, comparação e ordenação de notações numéricas devem tomar como ponto de partida os números que a criança conhece. Esse trabalho pode ser feito por meio de atividades em que, por exemplo, o professor: elabora, junto com os alunos, um repertório de situações em que usam números; pede aos alunos que recortem números em jornais e revistas e façam a leitura deles (do jeito que sabem); elabora, com a classe, listas com números de linhas de ônibus da cidade,números de telefones úteis, números de placas de carros, e solicita a leitura deles; orienta os alunos para que elaborem fichas onde cada um vai anotar os números referentes a si próprio, tais como: idade, data de nascimento,número do calçado, peso, altura, número de irmãos, número de amigos, etc; trabalha diariamente com o calendário para identificar o dia do mês e registrar a data; • solicita aos alunos que façam aparecer, no visor de uma calculadora,números escritos no quadro ou indicados oralmente; pede aos alunos que observem a numeração da rua onde moram, onde começa e onde termina, e registrem o número de suas casas e de seus vizinhos; verifica como os alunos fazem contagens e como fazem a leitura de números com dois ou mais dígitos e que hipóteses possuem acerca das escritas desses números. (PCN/EF/Matemática/ Anos Iniciais, p.65)

O documento alerta para a inadequação de apresentar-se prematuramente às crianças uma análise formal da constituição da escrita numérica e de denominações como unidades, dezenas e centenas:

Na prática escolar, no entanto, o mais comum é tentar explicitar, logo de início, as ordens que compõem uma escrita numérica - unidade, dezena, etc. 
- para que o aluno faça a leitura e a escrita dos números com compreensão. Embora isso possa parecer simples e natural do ponto de vista do adulto, que já conhece as regras de formação do sistema de numeração, o que se observa é que os alunos apresentam dificuldades nesse trabalho, deixando o professor sem compreender por que isso acontece (PCN/EF/Matemática/ Anos Iniciais, p.66)

No entanto, mesmo sem conhecer as regras do sistema de numeração decimal, as crianças são capazes de indicar qual é o maior número de uma listagem, em função da quantidade de algarismos presentes em sua escrita (justificam que 156 é maior que 76 porque tem mais "números"); também são capazes de escrever e interpretar números compostos por dois ou três algarismos. Para produzir escritas numéricas, alguns alunos recorrem à justaposição de escritas que já conhecem, organizando-as de acordo com a fala. Assim, por exemplo, para representar o 128, podem escrever 100208 (cem/vinte/ oito) ou 10020 e 8 (cem/vinte e oito). É importante que o professor dê a seus alunos a oportunidade de expor suas hipóteses sobre os números e as escritas numéricas, pois essas hipóteses constituem subsídios para a organização de atividades. (PCN/EF/Matemática/ Anos Iniciais,p.65)

O documento aponta ainda a perspectiva de se trabalhar com os números em situações-problema, explicitando suas diferentes funções:

Dentre as situações que favorecem a apropriação da ideia de número pelos alunos, algumas se destacam. Uma delas consiste em levá-los à necessidade de comparar duas coleções do ponto de vista da quantidade, seja organizando uma coleção que tenha tantos objetos quanto uma outra, seja organizando uma coleção que tenha o dobro, ou o triplo, etc., de uma outra, seja completando uma coleção para que ela tenha a mesma quantidade de objetos de uma outra.

Outra situação é aquela em que os alunos precisam situar algo numa listagem ordenada, seja para lembrar da posição de um dado objeto numa linha, ou de um jogador num jogo em que se contem pontos, ou para ordenar uma sequência de fatos, do primeiro ao último. Nessas situações, utilizarão diferentes estratégias como a contagem, o pareamento, a estimativa, o arredondamento e, dependendo da quantidade, até a correspondência de agrupamentos.

Os procedimentos elementares de cálculo, por sua vez, também contribuem para o desenvolvimento da concepção do número. Isso ocorre, por exemplo, quando precisam identificar deslocamentos (avanços e recuos) numa pista graduada; ou então quando necessitam indicar a quantidade de 
elementos de coleções que juntam, separam, repartem. (PCN/EF/Matemática/ Anos Iniciais, p.66)

As reflexões sobre o assunto prosseguiram em nossa atuação como pesquisadora e como assessora de projetos em escolas ou secretarias de educação.

Orientei o trabalho de Rodrigues (2001) que apresentou a dissertação de mestrado "Base dez: o grande tesouro matemático e sua aparente simplicidade". O estudo tinha como questão central identificar a trajetória da construção das escritas numéricas e de seu uso, ao longo do ensino fundamental e propunha-se a contribuir para a elaboração de propostas didáticas mais consistentes, que levassem em conta conhecimentos prévios dos alunos e alguns obstáculos que se interpõem nessa trajetória. Resgatava também a história do ensino do sistema de numeração nas séries iniciais do ensino fundamental nas últimas décadas. Em seu estudo, a pesquisadora buscou fontes de sustentação em investigações que realizaram estudos sobre a construção das escritas numéricas, mostrando, por exemplo, que o processo de construção das ideias e procedimentos envolvidos nos agrupamentos e trocas na base dez leva muito mais tempo para ser realizado do que se possa imaginar. Rodrigues entrevistou alunos da educação infantil e das diferentes etapas do ensino fundamental, analisando relações entre conhecimentos escolares e conhecimentos construídos socialmente pelos alunos.

Como resultados, além de comprovar várias das afirmações sobre o processo de construção das escritas numéricas de pesquisas como as de Lerner e Sadovsky (1996), mostrou a necessidade de um trabalho consistente em relação à produção de escritas numéricas para o cálculo escrito e mental e para a resolução de problemas que envolvem números naturais o que não vem sendo conseguido pelo uso de metodologias que apostam na tentativa de "explicar" o funcionamento do sistema de numeração decimal para as crianças.

Em 2007, orientei a dissertação de Bonaldo, sobre o tema "Investigações sobre números naturais e processos de ensino e aprendizagem desse tema no início da escolaridade". O objetivo era investigar o ensino e aprendizagem de números naturais, buscando identificar semelhanças e diferenças entre os resultados e indicações de pesquisas sobre a construção do conceito de números pelas crianças. Analisava as contribuições de Piaget, Kamii, Fayol, Lerner e Sadovsky e as implicações que essas pesquisas trouxeram e trazem para o trabalho em sala de aula, especialmente no ano inicial do Ensino Fundamental. Para realizar este estudo, primeiramente foi feito um levantamento bibliográfico e a análise de documentos curriculares oficiais e analisados cadernos de alunos. A pesquisadora organizou um questionário que foi respondido por 12 professores, coletando dados que possibilitassem realizar um estudo diagnóstico 
nessas turmas do ano inicial do Ensino Fundamental de três escolas públicas estaduais. O trabalho trouxe contribuições para observarmos como as diretrizes presentes nos documentos oficiais são traduzidas na prática dos professores em sala de aula. A pesquisadora conclui que a prática se realiza mediante um rol bastante desconexo de atividades. Não identificou atividades que tivessem como propósito o trabalho com seriação e classificação que marcaram as propostas da década de 70, tampouco atividades que estimulassem a percepção da função social dos números, conforme apontam orientações mais recentes. Com relação às escritas numéricas, as propostas se restringem à cópia da sequência numérica, sem qualquer preocupação de trabalhar com hipóteses das crianças nem com a observação de regularidades dessas escritas.

Além dos trabalhos de orientação desenvolvi pesquisas com grupos de professoras em processos de formação, especificamente sobre a questão dos números e do sistema de numeração decimal. Publiquei alguns resultados da pesquisa no artigo "Descobertas de professoras sobre o universo numérico das crianças: a construção de saberes por meio de pesquisas realizadas com seus alunos" nos anais do XIV Encontro Nacional de Didática da Matemática e Prática de Ensino, realizado em 2008 em Porto Alegre. Nesse artigo analisamos experiências as reflexões de um grupo de professoras ao se envolverem com as hipóteses e ideias de seus alunos sobre as escritas numéricas e como fizeram uso desses conhecimentos para o trabalho em sala de aula. Como resultados destacamos que a tarefa de construção dos números tem resultados muito interessantes quando as professoras passam a se envolver com as produções e ideias das crianças e a usá-las para que elas as ampliem..

Experiências como essas, reunindo pequenos grupos de professoras puderam ser realizadas em maior escala, em alguns projetos. Um deles foi desenvolvido a convite do Instituto Abaporu de Educação e Cultura e constitui-se como um Programa de Formação de Professores em Educação Matemática - PROFEMAT - que vem sendo desenvolvido junto aos professores dos cinco anos iniciais, em todo o Estado do Acre desde 2009. Publiquei alguns resultados sobre a implementação desse projeto num artigo intitulado "Educação Matemática nas escolas dos povos da floresta: formação de professores dos anos iniciais", na revista Educação Matemática Pesquisa, em 2011. No Projeto, as propostas de trabalho com os números baseiam-se nos resultados das pesquisas mais recentes e sua utilização pelos professores vem trazendo bons resultados. O foco são as experiências reais das crianças com os números e o material dourado foi abolido. Outra experiência foi realizada na Secretaria Municipal de Educação de São Paulo, em que participei da coordenação e elaboração de Orientações Curriculares e de Cadernos e Vídeos de Apoio ao trabalho dos professores, materiais em que também são discutidas formas de 
abordagem dos números naturais e do sistema de numeração decimal e que levem em conta os conhecimentos prévios dos alunos e suas hipóteses. Num projeto de pesquisa em que fazemos uma avaliação do uso desse material pelos professores que vimos desenvolvendo também já é possível identificar a relação dos professores quando descobrem que seus alunos pensam, falam e fazem registros sobre números e outros temas matemáticos.

\section{A magia das crianças e de suas produções}

Faço referência a essas várias experiências vivenciadas, seja em função de orientações de trabalhos de pesquisa ou da condução de projetos, acompanhando o trabalho de professoras e de suas crianças, em diferentes escolas brasileiras, para explicar que fui contagiada pela magia das crianças e de suas produções. Na diversidade de propostas que acompanhamos, alguns pontos comuns e de grande simplicidade se destacam e mostram-se reveladores.

Um deles refere-se a estimular e a ouvir o que as crianças têm a dizer sobre a matemática que vão descobrindo em sua vida, todos os dias e sobre suas hipóteses sobre escritas numéricas, procedimentos de resolução de problema, de realizar cálculos, formas de compreender o espaço, de representar formas, de medir, de comparar grandezas, de ler dados apresentados em tabelas ou gráficos. Usar essas hipóteses e descobertas como indicações de possíveis trajetórias de aprendizagem a serem percorridas pelas crianças pode parecer algo muito óbvio. Mas não é, e faz toda a diferença. Como exemplo, transcrevemos um repertório de alunos de 5/6 anos anotado por professora de turma de escola localizada em São Paulo, a partir da pergunta "para que servem os números?"

Para saber o número da casa. Para marcar datas importantes. Para saber o dia no calendário. Para a contagem quando lança um foguete. Para saber o dia do aniversário. Para medir na régua. Para saber quantos anos temos. Para saber o nosso peso. Para saber o nosso tamanho. Para saber as horas. Para fazer contas. Para saber os dias, até o 31. Para pagar e saber quanto custa. Para usar a calculadora. Para saber o número da roupa. Para contar o dinheiro. Para ver a placa de velocidade na estrada. Para saber o grau da lente dos óculos. Para saber o número dos documentos dos pais. Para contar coisas.

Outro episódio a registrar ocorreu numa escola na periferia de Salvador. Trabalhando com uma professora de primeiro ano perguntávamos se ela sabia que números seus alunos conheciam. 
Ela nos respondeu que ainda não havia trabalhado conteúdos matemáticos com eles mas supunha que conhecessem alguns números de 1 a 9 . Pedimos que ela convidasse duas crianças para que conversássemos com elas e pudéssemos ter resposta para a pergunta. Com conversas e um simples ditado de números, ajudamos a professora a descobrir que Milena, de 6 aos, e Daniel, de 7 anos, ambos cursando o primeiro ano de escolaridade e que, segundo sua professora, talvez nem conhecessem os números de 1 a 9 , tinham muitos conhecimentos sobre a escrita numérica, como mostram alguns protocolos produzidos por eles, que mostramos a seguir.

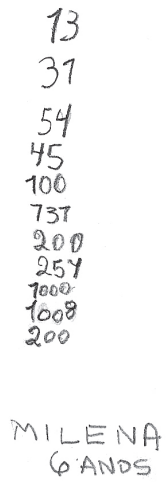

Números ditados a Milena:

$13 ; 31 ; 54 ; 45 ; 100 ; 131 ; 200 ; 254 ; 1000 ; 108 ; 200$.

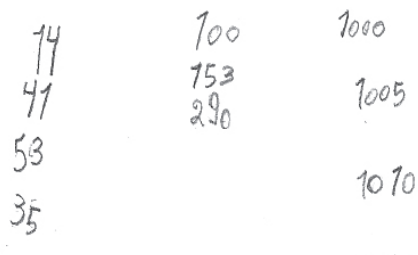

100200

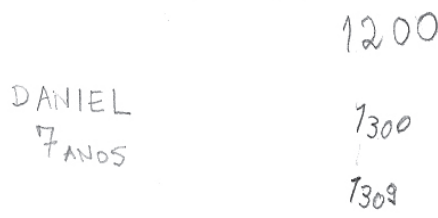

Números ditados a Daniel:

$14 ; 41 ; 53 ; 35 ; 100 ; 153 ; 290 ; 1000 ; 1005 ; 1010 ; 1200 ; 1300 ; 1309$. 
Em episódios como esse, é possível verificar que as crianças de 6-7 anos produzem escritas convencionais para grande parte dos números ditados - a exceção foi para o número 108, no caso de Milena e do 1.200, no caso de Daniel - revelando um rico repertório sobre os números, mas que, frequentemente, é pouco utilizado em sala de aula.

Enquanto trabalhava com as professoras, perguntava-me que finalidade teria o uso do material dourado para explicar a Milena e a Daniel o que eles já observaram: que 13 e 31 são escritos com os mesmos algarismos, mas que dependendo da posição do algarismo ele tem valor diferente.

Ao mesmo tempo, persistia a indagação das professoras. Mas e quando chegarmos nas técnicas operatórias. Como vamos fazer?

Tradicionalmente - e ainda hoje - tinha-se a ideia de que as crianças somente podem resolver um problema se tivessem um modelo para seguir. Treinava-se a resolução de determinados tipos de problema, associava-se a escolha das operações a algumas palavras-chave e criava-se uma dependência da criança em relação à orientação do professor para a escolha da operação. Da mesma forma elas só podiam operar se ensinássemos a elas uma técnica operatória.

Mais uma vez as crianças nos mostraram seus caminhos. Desta vez relato parte do episódio que o ocorre numa escola em São Paulo, em que a professora apresenta problemas às crianças de primeiro ano para que resolvam "do seu jeito". Dentre as várias soluções, destacamos duas apenas a título de exemplificação.

Em uma escola há alguns meninos e 30 meninas. No total são 84 crianças. Quantos meninos há na escola?

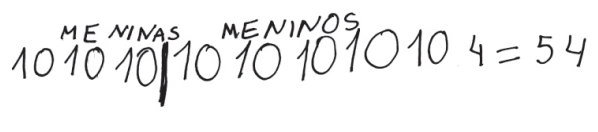

$$
\text { Milena (7 anos) - Escola de São Paulo }
$$

Marcos tinha 78 figurinhas e ganhou 45 de seu tio. Quantas figurinhas ele tem agora?

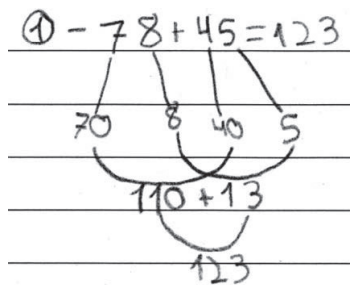

Roberto (7 anos) - Escola de São Paulo 
Novamente, essas soluções, nos remetem a formular questões como por exemplo:

- Em que medida ajudaríamos esta Milena paulistana explicando que poderia representar 84 por 8 barras e 4 cubinhos (que não têm nada a ver com meninos e meninas de uma escola) e retirar 3 barras, obtendo cinco barras e quatro cubinhos e que seriam convertidas na escrita 54 ?

- Em que medida ajudaríamos Roberto explicando que poderia representar 78 por 7 barras e 8 cubinhos, juntar mais 4 barras e 5 cubinhos (que não têm nada a ver com as figurinhas de Marcos) e juntar primeiro os cubinhos (totalizando 13), trocar 10 deles por uma barra e juntar as barras totalizando 12 e trocando 10 barras por uma placa de cem, para chegar à escrita 123 .

Imaginamos que o material dourado que supúnhamos ser um material concreto, na verdade não funciona como tal. O que significa concreto? O simples fato de ser composto de objetos que a criança pode manipular? E o que dizer dos diferentes registros a serem compreendidos e relacionados pelas crianças, quando se usa o material? Seria mesmo um elemento facilitador?

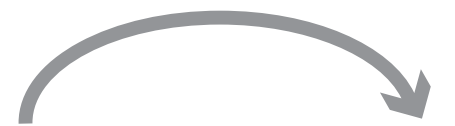

Entes reais

(bolinhas, figurinhas, crianças, dinheiro, etc)

\section{Representação}

por meio do material

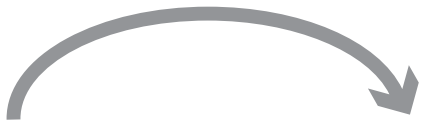

Representação

escrita

\section{8}
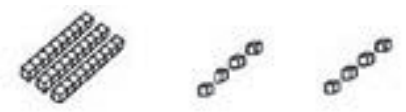

Analisando o que é veiculado por revistas que chegam aos professores, observamos que ainda prevalece um discurso genérico e inconsistente de que o uso de "materiais concretos" resolve problemas de aprendizagem, de que eles são motivadores, bons aliados nas aulas de Matemática. Esse discurso precisa ser questionado. Isso não significa que se generalize a afirmação para todos os tipos de recursos. Mas é preciso investigar melhor algumas orientações que circulam e chegam aos professores, até em documentos de caráter oficial. 


\section{Os desafios da formação de professores dos anos iniciais}

Nas várias experiências vivenciadas observamos que, decorridos já cerca de quinze anos da elaboração e discussão dos PCN, a análise das atividades apresentadas em diferentes materiais e, inclusive em livros didáticos aprovados pelo PNLD, mostram propostas de trabalho que misturam várias concepções e que não se atualizam em função de resultados de pesquisa.

Por outro lado, nos cursos de formação inicial e continuada de professores, quando se discute o ensino de Matemática, o tema é apresentado isento de qualquer referência teórica, sem tematizar a prática docente em relação ao que as pesquisas revelam.

Além disso, textos orientadores divulgados em projetos de formação do Ministério da Educação, que circulam pelo país, a nosso ver não trazem questões para o debate e apenas reforçam concepções e práticas bastante tradicionais, frente aos avanços da pesquisa.

Claro que o Material Dourado, que focalizamos neste artigo é apenas um exemplo. Há muitas discussões em jogo, como é o caso dos "materiais concretos para ensinar frações", entre outros. Considero que está mais que na hora de discutir profundamente o uso dos chamados materiais concretos para a aprendizagem em Matemática, especialmente nos anos iniciais, considerando tudo que foi desvelado em relação às hipóteses das crianças por pesquisas recentes. Ou continuaremos indefinidamente produzindo resultados de pesquisa que não serão usados para melhorar as aprendizagens das crianças?

\section{Referências}

BRASIL. Ministério da Educação e do Desporto. Secretaria de Educação Fundamental. Parâmetros Curriculares Nacionais: Primeiro e Segundo Ciclos do Ensino Fundamental. Brasília, DF, 1997. Disponível em: <http://portal.mec.gov.br/index. php?option $=$ com_content\&view=article\&id=12640:parametros-curriculares-nacionais1o-a-4o-series\&catid=195:seb-educacao-basica $>$. Acesso em 11 mar. 2012.

BONALDO, I. M. Investigações sobre números naturais e processos de ensino e aprendizagem desse tema no início da escolaridade. 2007. Mestrado. PUC/SP Disponível em: http://www.pucsp.br/pos/edmat/mp/dissertacao/iclea_bonaldo.pdf. Acesso em: 11 mar. 2012.

CONSTANCE, K. A criança e o Número: Implicações Educacionais da Teoria de Piaget para a atuação junto a escolares de 4 a 6 anos. Tradução por Regina A. de Assis. 28. ed. Campinas: Papirus, 2001.

FAYOL, M. A Criança e o Número: Da contagem à resolução de problemas. Tradução por Rosana Severino de Leoni. Porto Alegre: Artes Médicas, 1996. 
INSTITUT Nacional de Recherche Pédagogique. Un, deux, beaucoup... passionement: les enfants et les nombres. Rencontre Pédagogique, 21. Paris: INRP, 1988.

LERNER, D. e SADOVSKY, P. O sistema de numeração: um problema didático. In: PARRA, Cecília; SAIZ Irmã; [et al] (Org.). Didática da Matemática: Reflexões Psicopedagógicas. Tradução por Juan Acuña Llorens. Porto Alegre: Artes Médicas, 1996. p. 73-155.

PIRES, C. M. C. Educação Matemática: conversas com professores dos anos iniciais. São Paulo. Zapt Editora.2012.

Descobertas de professoras sobre o universo numérico das crianças: a construção de saberes por meio de pesquisas realizadas com seus alunos. In: Anais do Encontro Nacional de Didática e Prática de Ensino (ENDIPE), 2008, Porto Alegre.

. DUTOIT, R. . Educação Matemática nas escolas dos povos da floresta: formação de professores dos anos iniciais. Educação Matemática Pesquisa (Impresso), v. 13 no., p. 291-312, 2011.

RODRIGUES, W. S. Base dez: o grande tesouro matemático e sua aparente simplicidade. 2001. 188f. Dissertação (Mestrado em Educação Matemática) - Programa de Pós-Graduação em Educação Matemática, Pontifícia Universidade Católica de São Paulo, São Paulo, 2001. Disponível em: <http://www.sapientia.pucsp.br/tde_busca/ arquivo.php?codArquivo=6046> . Acesso em: 11 mar. 2012.

SÃO PAUlO (Estado) Secretaria da Educação. Guias Curriculares Propostos Para As Matérias do Núcleo Comum do Ensino do 1. ${ }^{\circ}$ Grau. 1979.

SÃO PAULO (Estado) Secretaria da Educação. Coordenadoria de Estudos e Normas Pedagógicas. Subsídios para a implementação do guia curricular de Matemática: Álgebra para o $\mathbf{1}^{\mathbf{0}}$ grau $-\mathbf{1}^{\mathrm{a}}$ a $\mathbf{4}^{\text {a }}$ séries. 2.ed. São Paulo: SE/CENP, 1979.

SÃO PAULO (Estado) Secretaria da Educação. Proposta Curricular para o Ensino de Matemática: 1. ${ }^{\circ}$ Grau. São Paulo: SE/CENP, 1986.

Submetido em maio de 2012 Aprovado em setembro de 2012 